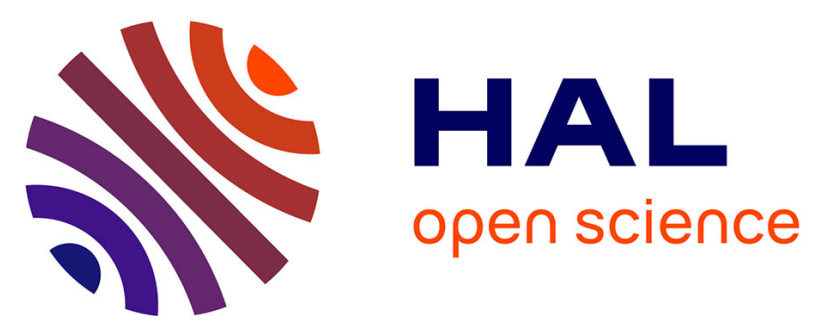

\title{
Synthesis, structures, and single-molecule magnet behaviour of high-nuclearity nickel(II) dicubane-type complexes with pyridyl-alcohol-ligands
}

Sophie Hameury, Laure Kayser, Roberto Pattacini, Patrick Rosa, Anne-Laure Barra, Pierre Braunstein

\section{To cite this version:}

Sophie Hameury, Laure Kayser, Roberto Pattacini, Patrick Rosa, Anne-Laure Barra, et al.. Synthesis, structures, and single-molecule magnet behaviour of high-nuclearity nickel(II) dicubanetype complexes with pyridyl-alcohol-ligands. ChemPlusChem, 2015, 80 (8), pp.1312-1320. 10.1002/cplu.201500184 . hal-01199283

\section{HAL Id: hal-01199283 \\ https://hal.science/hal-01199283}

Submitted on 27 Jan 2021

HAL is a multi-disciplinary open access archive for the deposit and dissemination of scientific research documents, whether they are published or not. The documents may come from teaching and research institutions in France or abroad, or from public or private research centers.
L'archive ouverte pluridisciplinaire HAL, est destinée au dépôt et à la diffusion de documents scientifiques de niveau recherche, publiés ou non, émanant des établissements d'enseignement et de recherche français ou étrangers, des laboratoires publics ou privés. 


\title{
Synthesis, Structures and Single Molecule Magnet Behaviour of High Nuclearity Ni(II) Dicubane-type Complexes with Pyridyl- Alcohol Ligands
}

\author{
Sophie Hameury, ${ }^{[\mathrm{a}]}$ Laure Kayser, ${ }^{[\mathrm{a}]}$ Roberto Pattacini, ${ }^{[\mathrm{a}]}$ Patrick Rosa,${ }^{*[\mathrm{~b}]}$ Anne-Laure Barra ${ }^{[\mathrm{c}]}$ and \\ Pierre Braunstein ${ }^{\star[a]}$
}

Dedicated to Prof. Malcolm Chisholm on the occasion of his

70th birthday, with our congratulations for his outstanding

achievements and our warmest wishes.

\begin{abstract}
The condensation reaction between two chemically different tetranuclear cubane-like clusters $\left[\mathrm{Ni}\left(\mu_{3}-\mathrm{Cl}\right)(\mathrm{Cl})(\mathrm{HL})\right]_{4}(\mathbf{1})(\mathrm{HL}$ $=2$-methyl-1-(pyridin-2-yl)propan-2-ol) and $\left[\mathrm{Ni}\left(\mu_{3}-\mathrm{OH}\right)(\mathrm{Cl})(\mathrm{HL})\right]_{4}(\mathbf{2})$ is shown to provide a new access to higher nuclearity complexes, as shown with the synthesis of the octanuclear complex $\left[\mathrm{Ni}_{8}\left(\mu_{3}-\mathrm{Cl}\right)_{3}\left(\mu_{3^{-}}\right.\right.$ $\mathrm{OH})_{5}\left(\mu-\mathrm{Cl}_{2} \mathrm{Cl}_{6}(\mathrm{HL})_{7}\right](3)$. In one instance, we also isolated the heptanuclear complex $\left[\mathrm{Ni}_{7}\left(\mu_{3}-\mathrm{Cl}\right)_{2}\left(\mu_{3}-\mathrm{OH}\right)_{6} \mathrm{Cl}_{4}\left(\mathrm{H}_{2} \mathrm{O}\right)_{2}(\mathrm{HL})_{6}\right] \mathrm{Cl}_{2} \quad$ (4). Magnetic properties measured by SQUID susceptometry evidenced $S=8$ and $S=5$ ground states for complexes 3 and 4 , respectively. In particular, ac susceptometry evidenced slow relaxation of the magnetization for complex $\mathbf{3}$, and suggests a similar behaviour at sub-kelvin temperatures for complex 4 .
\end{abstract}

\section{Introduction}

The coordination chemistry of ligands possessing significantly different donor groups, also called hybrid ligands, is attracting increasing interest in diverse areas of chemistry. Their successful applications in homogeneous catalysis results from the possibility of a fine tuning of the catalytic properties through chemical modifications of the donor functions. Furthermore, their different affinities for the metal centre can lead to enhanced reactivity and hemilabile behaviour. ${ }^{[1]}$ Such ligands may also provide access to metal complexes with unusual structures, possibly endowed with interesting catalytic and/or magnetic properties. This has been observed, in particular, with pyridinealcohol or pyridine-alcoholate ligands, where N,O chelation and O-bridge formation can result in polynuclear complexes with

[a] S. Hameury, L. Kayser, Dr. R. Pattacini, Dr. P. Braunstein Laboratoire de Chimie de Coordination, UMR 7177 CNRS/Université de Strasbourg, Institut Le Bel

4, rue Blaise Pascal, CS90032, 67081 Strasbourg Cedex, France

E-mail: braunstein@unistra.fr

[b] Dr. P. Rosa

CNRS, Université de Bordeaux, ICMCB, UPR 9048

F-33600 Pessac, France

E-mail: patrick.rosa@icmcb.cnrs.fr

[c] Dr. A.-L. Barra

Laboratoire National des Champs Magnétiques Intenses

CNRS, Université Joseph Fourier

25 Avenue des Martyrs, 38402 Grenoble Cedex 9, France

Supporting information for this article is given via a link at the end of the document. unpredictable structures. The rich chemistry of 2-pyridone and of deprotonated pyridine-2-ylmethanolate $\left(\mathrm{L}_{\mathrm{Me}}{ }^{-}\right)$, derived from pyridine-2-ylmethanol $\left(\mathrm{HL}_{\mathrm{Me}}\right.$ Scheme 1$)$ is well documented. ${ }^{[2]}$<smiles>CCc1cccc(CCO)n1</smiles>

Scheme 1.

Motivated by the versatility of this type of ligands, we previously focused our interest on the synthesis of $\mathrm{Ni}(\mathrm{II})$ complexes for applications in the catalytic oligomerization of ethylene. ${ }^{[3]}$ Further work showed that deprotonation of the alcohol function resulted in unexpected mixed nickel/sodium polynuclear complexes. Thus, coordination clusters such as $\left[\mathrm{Ni}_{7}\left(\mathrm{~L}_{\mathrm{Me}}\right)_{12}\right] \mathrm{Cl}_{2}$, $\left[\mathrm{Na}_{3} \mathrm{Ni}_{4}\left(\mathrm{~L}_{\mathrm{Me}}\right)_{9}\left(\mu_{3}-\mathrm{OH}\right)\right] \mathrm{Cl}$ and $\left[\mathrm{NaNi}_{6}\left(\mathrm{~L}_{\mathrm{Me}}\right)_{12}\right] \mathrm{Cl}$ (Figure 1) were isolated and fully characterized when $\mathrm{NaH}$ was used as a base. Their formation depends on the reagents stoichiometry. ${ }^{[4]}$

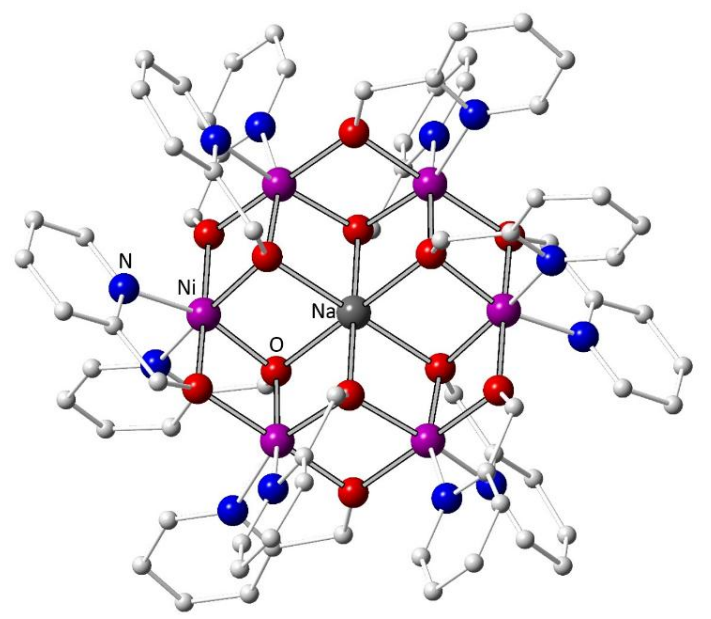

Figure 1. View of the structure of the cation in $\left[\mathrm{NaNi}_{6}\left(\mathrm{~L}_{\mathrm{Me}}\right)_{12}\right] \mathrm{Cl}^{[4 \mathrm{~b}]}$ 
The structural diversity observed with pyridine-alcoholate ligands encouraged us to explore further the coordination chemistry of pyridine alcohol ligands and we isolated, in the absence of $\mathrm{NaH}$, tetranuclear, cubane-like transition metal dihalido complexes $\left[\mathrm{Ni}\left(\mu_{3}-\mathrm{Cl}\right) \mathrm{Cl}(\mathrm{HL})\right]_{4} \quad(\mathbf{1}){ }^{[5]} \quad$ Another cubane-type complex, $\left[\mathrm{Ni}\left(\mu_{3}-\mathrm{OH}\right) \mathrm{Cl}(\mathrm{HL})\right]_{4}(\mathbf{2})$, was prepared by reaction of $\mathbf{1}$ with an excess of highly dispersed $\mathrm{NaOH}$, prepared in situ by hydrolysis of $\mathrm{NaH}$, and the hydroxide anion selectively substituted the chloride corners without deprotonating the 2-methyl-1-(pyridin-2yl)propan-2-olligand ( $\mathrm{HL}$ ) (Scheme 2). The magnetic properties of these cubanes were investigated and unveiled a SingleMolecule Magnet (SMM) behaviour. ${ }^{[5]}$

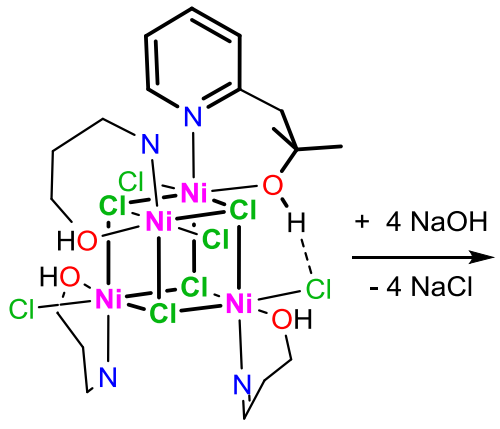

1

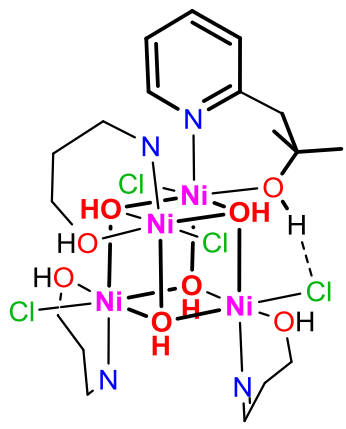

2
Scheme 2. For the known cubane-type complexes 1 and 2 , one $\mathrm{N}, \mathrm{OH}$ chelating ligand is explicitly depicted but only the chelate cycle is displayed for the remaining three. ${ }^{[5]}$

The chemistry of complex 1 proved to be even richer, since in the course of these studies, we managed to isolate the new, higher nuclearity clusters $\left[\mathrm{Ni}_{8}\left(\mu_{3}-\mathrm{Cl}\right)_{3}\left(\mu_{3}-\mathrm{OH}\right)_{5}(\mu-\mathrm{Cl})_{2} \mathrm{Cl}_{6}(\mathrm{HL})_{7}\right](3)$ and $\left[\mathrm{Ni}_{7}\left(\mu_{3}-\mathrm{Cl}\right)_{2}\left(\mu_{3}-\mathrm{OH}\right)_{6} \mathrm{Cl}_{4}\left(\mathrm{H}_{2} \mathrm{O}\right)_{2}(\mathrm{HL})_{6}\right] \mathrm{Cl}_{2}$ (4). We studied the formation of the octanuclear complex $\mathbf{3}$ and were able to rationalize it. We also describe here the magnetic behaviour of both complexes.

\section{Results and Discussion}

\section{Syntheses and Structures.}

The ligand 2-methyl-1-(pyridin-2-yl)propan-2-ol (HL) was synthesized according to published procedures, by condensation of lithiated 2-picoline with acetone. ${ }^{[6]}$ In the course of numerous attempts aimed at rationalizing the synthesis of $\left[\mathrm{Ni}\left(\mu_{3}-\mathrm{OH}\right) \mathrm{Cl}(\mathrm{HL})\right]_{4} \quad(2)$ by varying the $\mathrm{NaOH} / \mathrm{HL}$ ligand stoichiometry, we isolated the octanuclear cluster $\left[\mathrm{Ni}_{8}\left(\mu_{3}-\mathrm{Cl}\right)_{3}\left(\mu_{3}-\mathrm{OH}\right)_{5}\left(\mu-\mathrm{Cl}_{2} \mathrm{Cl}_{6}(\mathrm{HL})_{7}\right] \quad\right.$ (3) in low yields. The structure of $\mathbf{3}$ was determined by single crystal $\mathrm{X}$-ray diffraction (Figure 2, Table 1).

Each $\mathrm{Ni}(\mathrm{II})$ centre is hexacoordinated and shows a slightly distorted octahedral coordination geometry. Five of the metal

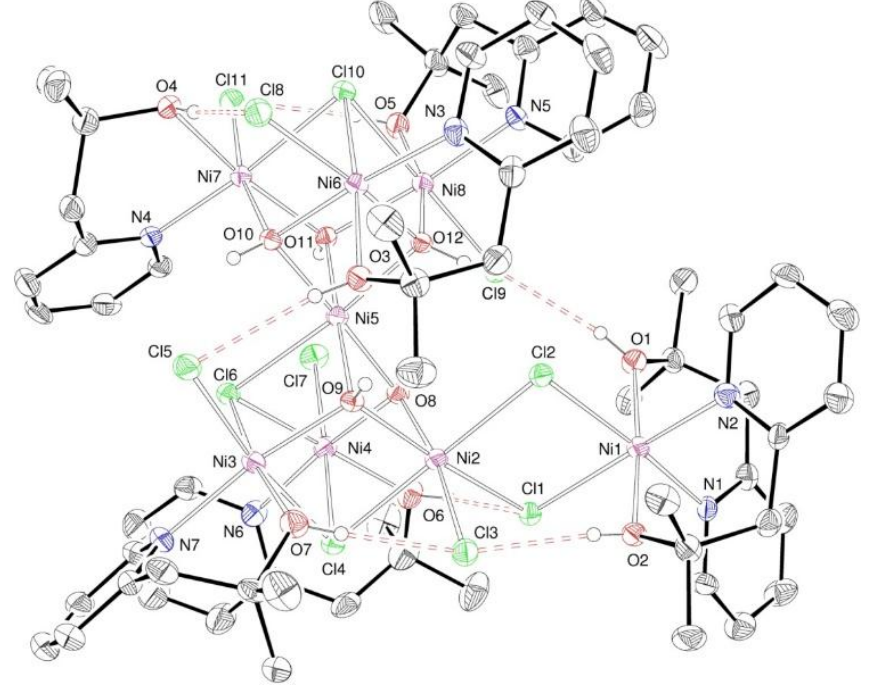

Figure 2. ORTEP of the molecular structure of $\mathbf{3}$. Thermal ellipsoids are at $40 \%$ probability. Hydrogen atoms are omitted for clarity, except those bound to alcohol oxygen atoms. Hydrogen bonds are depicted with red dashed lines. Selected bond distances $(\AA)$ : Ni1-O1 2.065(3), Ni1-O2 2.054(3), Ni1-N1 2.097(4), Ni1-N2 2.098(4), Ni1-Cl1 2.474(1), Ni1-Cl2 2.405(1), Ni2-O8 2.034(3), Ni2-O9 2.017(3), Ni2-Cl2 2.443(1), Ni2-Cl1 2.423(1), Ni2-Cl3 2.469(1), Ni2-Cl4 2.463(1), Ni3-O7 2.057(4), Ni3-O9 1.994(3), Ni3-N7 2.081(4), $\mathrm{Ni3}-\mathrm{Cl} 4$ 2.586(1), Ni3-Cl5 2.420(1), Ni3-Cl6 2.431(1), Ni4-O6 2.066(4), Ni4-O8 2.007(3), Ni4-N6 2.080(4), Ni4-Cl4 2.587(1), Ni4-Cl6 2.506(1), Ni4-Cl7 2.370(1), Ni5-O8 2.041(3), Ni5-O9 2.063(3), Ni5-O10 2.034(3), Ni5-O11 2.045(3), Ni5-O12 2.061(3), Ni5-Cl6 2.478(1), Ni6-O3 2.102(4), Ni6-O10 2.030(3), Ni6-O12 2.067(3), Ni6-N3 2.089(4), Ni6-Cl8 2.407(1), Ni6-Cl10 2.463(1), Ni7-O4 2.115(4), Ni7-O10 2.056(3), Ni7-O11 2.054(3), Ni7-N4 2.068(4), Ni7-Cl10 2.500(1), Ni7-Cl11 2.405(1), Ni8-O5 2.086(4), Ni8-O11 2.034(3), Ni8-O12 2.039(3), Ni8-N5 2.081(4), Ni8-Cl9 2.394(1), Ni8-Cl10 2.511(1). For selected bond angles, see Table S1 in ESI.

centres ( $\mathrm{Ni3}, \mathrm{Ni} 4, \mathrm{Ni}, \mathrm{Ni7}$ and $\mathrm{Ni8}$ ) are chelated by $\mathrm{HL}$ through the $\mathrm{O}$ and $\mathrm{N}$ donors, while one is doubly chelated (Ni1). The remaining two nickel centres are not coordinated by $\mathrm{HL}$ ( $\mathrm{Ni2}$ and $\mathrm{Ni5}$ ). A heptanuclear dicubane core can be recognized within the structure. The two cubane moieties share a common vertex represented by a $\mathrm{Ni}$ cation (Ni5). Within this subunit, the metal centres are capped by chloride and hydroxide anions, in an asymmetric fashion. One of the cubanes (containing Ni6-Ni8, Figure 3) is associated with one $\mathrm{Cl}^{-}$and three $\mathrm{OH}^{-}$triply bridging anionic ligands, while the second (containing Ni2-Ni4, Figure 3) contains two chlorides and two hydroxide ligands. Six terminal halides are coordinated to six of the seven nickel centres. Two bridging chlorides connect a non $\mathrm{N}, \mathrm{O}$ chelated metal centre (Ni2) of the $\mathrm{Ni}_{7}$ dicubane with a mononuclear fragment which contains the only doubly chelated $\mathrm{Ni}(\mathrm{II})$ cation (Ni1). Multiple intramolecular hydrogen bonds are present between the alcohol functions and neighbouring terminal chlorides. The nearest nickel centre to $\mathrm{Ni1}$ in another molecule is $\mathrm{Ni}$, at a distance of $8.998(1) \AA$. This distance is too long to influence significantly the magnetic properties of 3 (see below). To the best of our knowledge, only two examples of dicubane $\mathrm{Ni}(\mathrm{II})$ structures sharing a common vertex have been reported to date. ${ }^{[7]}$ 


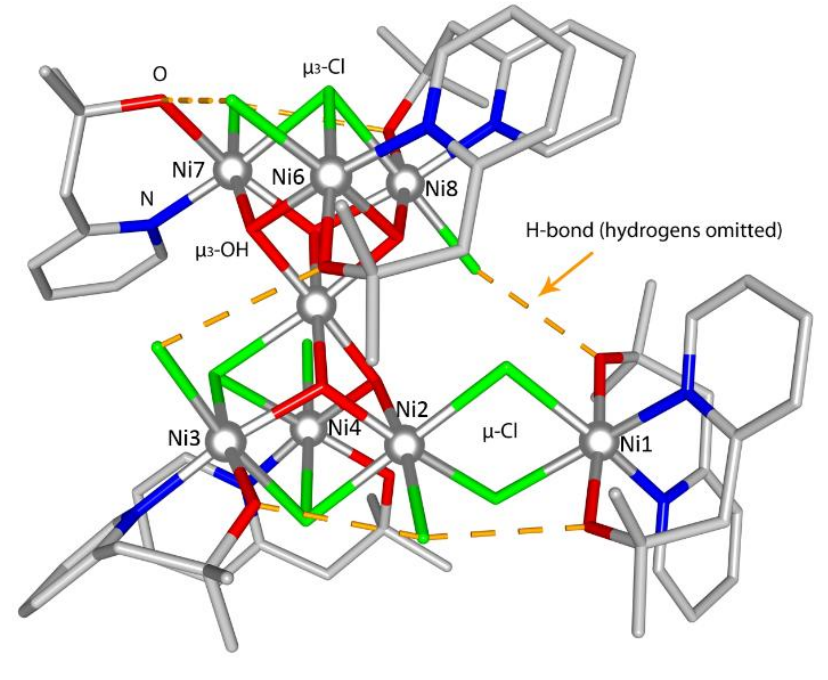

Figure 3. Simplified diagram of the solid state structure of $\mathbf{3}$.

We first hypothesized that 3 could be an intermediate in the formation of $\mathbf{2}$ from the reaction of $\mathbf{1}$ with $\mathrm{NaOH}$. Indeed $\mathbf{3}$ displays an $\mathrm{OH} / \mathrm{Cl}$ ratio $(5 / 11)$ lower than that observed in 2 . Equations (1) and (2) could account for this reaction sequence.

$$
\begin{aligned}
& 2\left[\mathrm{Ni}\left(\mu_{3}-\mathrm{Cl}\right) \mathrm{Cl}(\mathrm{HL})\right]_{4}(\mathbf{1})+5 \mathrm{NaOH} \rightarrow \\
& \quad\left[\mathrm{Ni}_{8}\left(\mu_{3}-\mathrm{Cl}\right)_{3}\left(\mu_{3}-\mathrm{OH}\right)_{5}(\mu-\mathrm{Cl})_{2} \mathrm{Cl}_{6}(\mathrm{HL})_{7}\right](\mathbf{3})+\mathrm{HL}
\end{aligned}
$$

$\left[\mathrm{Ni}_{8}\left(\mu_{3}-\mathrm{Cl}\right)_{3}\left(\mu_{3}-\mathrm{OH}\right)_{5}\left(\mu-\mathrm{Cl}_{2}\right)_{6}(\mathrm{HL})_{7}\right](3)+3 \mathrm{NaOH}+\mathrm{HL} \rightarrow$

$$
2\left[\mathrm{Ni}\left(\mu_{3}-\mathrm{OH}\right) \mathrm{Cl}(\mathrm{HL})\right]_{4}(2)
$$

However, the reaction of $\mathbf{1}$ with a stoichiometric amount or an excess of $\mathrm{NaOH}$ pellets (eq 1 ) did not lead to 2 and only $\mathbf{3}$ was observed when the latter reaction was monitored by IR spectroscopy. This suggested that when 2 is formed, it reacts rapidly with unreacted $\mathbf{1}$ to give 3 (Scheme 3 ). The reaction $3 / 41+5 / 42 \rightarrow 3$ would thus be faster than the reaction $1+4 \mathrm{NaOH} \rightarrow \mathbf{2}$, preventing detection of the latter cluster in the course of the reaction since it is consumed almost as soon as formed. However, cluster 2 could be obtained in ca. 30\% yield when highly dispersed $\mathrm{NaOH}$, prepared in situ by hydrolysis of $\mathrm{NaH}$, was reacted with $1 .{ }^{[5]}$ We previously found that 3 could be obtained when $\mathrm{NaOH}$ pellets were used in excess (4.2 equiv. based on $\mathrm{Ni}$ ), owing to the lower reactivity of $\mathrm{NaOH}$ in this form and consequently slower $\mathrm{Cl} / \mathrm{OH}$ rate of substitution (see above). This favours the reaction $\mathbf{1}+\mathbf{2} \rightarrow \mathbf{3}$ vs. the reaction $1+4 \mathrm{NaOH} \rightarrow 2$. We have now found that the direct reaction of 1 with $\mathbf{2}$ gave 3 in better yield (Scheme 3).

Whereas the condensation between two identical nickel(II) tetranuclear cubanes has been previously observed, ${ }^{[7 b]}$ the reaction between 1 and 2 represents, to the best of our knowledge, the first example of condensation between two chemically different cubanes. Such a synthetic approach should have a high potential in view of its versatility.
In the course of reactions leading to the formation of complex 3, we isolated once a new complex $\left[\mathrm{Ni}_{7}\left(\mu_{3}-\mathrm{Cl}\right)_{2}\left(\mu_{3}-\mathrm{OH}\right)_{6} \mathrm{Cl}_{4}\left(\mathrm{H}_{2} \mathrm{O}\right)_{2}(\mathrm{HL})_{6}\right] \mathrm{Cl}_{2}$ (4). Its structure was determined by single crystal X-ray diffraction (Figures 4 and 5 and Table 1).

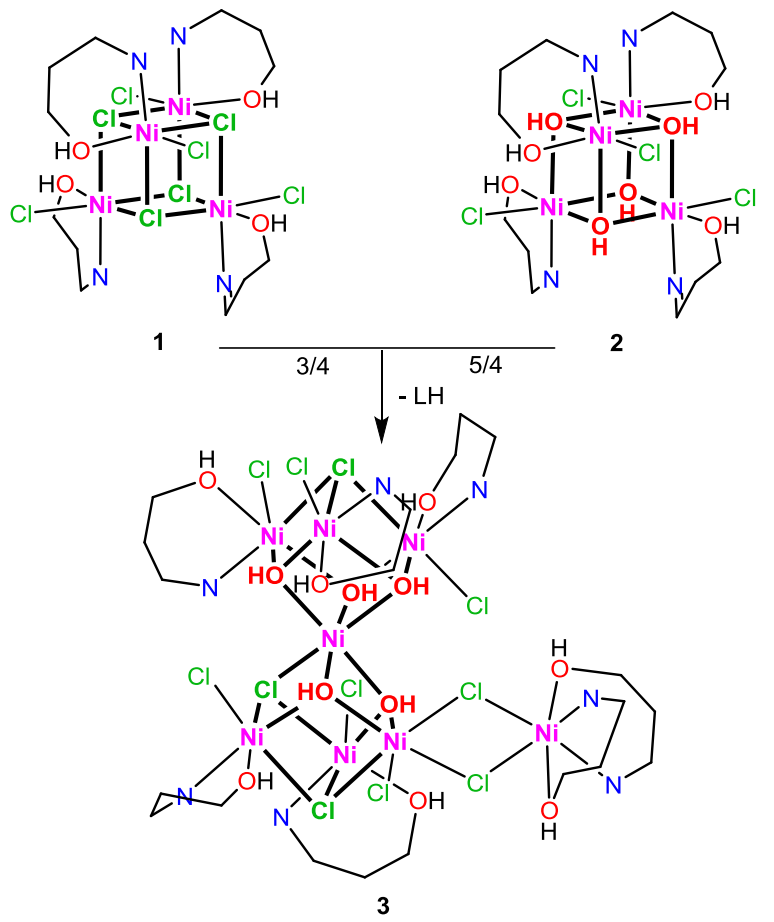

Scheme 3. Condensation of two chemically-different Ni(II) cubanes leading to the formation of the octanuclear complex 3 .

\begin{tabular}{|c|c|c|c|c|c|}
\hline \multirow[b]{2}{*}{$\begin{array}{l}\mu_{3}-\mathrm{OH}, \\
\mu_{3}-\mathrm{OH}\end{array}$} & \multicolumn{2}{|c|}{ Cluster 3} & \multirow[b]{2}{*}{$\begin{array}{l}\mu_{3}-\mathrm{Cl}, \\
\mu_{3}-\mathrm{Cl}\end{array}$} & \multicolumn{2}{|c|}{ Cluster $4 \cdot 2 \mathrm{CH}_{2} \mathrm{Cl}_{2}$} \\
\hline & $\begin{array}{l}\mu_{3}-\mathrm{OH} \\
\mu_{3}-\mathrm{Cl}\end{array}$ & $\begin{array}{l}\mu_{2}-\mathbf{C l}, \\
\mu_{2}-\mathbf{C l}\end{array}$ & & $\begin{array}{l}\mu_{3}-\mathrm{OH} \\
\mu_{3}-\mathrm{OH}\end{array}$ & $\begin{array}{l}\mu_{3}-\mathrm{OH} \\
\mu_{3}-\mathrm{Cl}\end{array}$ \\
\hline $\mathrm{Ni5}-\mathrm{Ni} 2$ & $\mathrm{Ni2}-\mathrm{Ni3}$ & $\mathrm{Ni} 1-\mathrm{Ni} 2$ & $\mathrm{Ni3-Ni4}$ & $\mathrm{Ni02-Ni3}$ & $\mathrm{Ni1-Ni3}$ \\
\hline $3.1029(9)$ & $3.3090(9)$ & $3.5893(9)$ & $3.7950(8)$ & $3.063(1)$ & $3.319(1)$ \\
\hline Ni5-Ni6 & $\mathrm{Ni2}-\mathrm{Ni4}$ & & & $\mathrm{Ni02-Ni2}$ & $\mathrm{Ni3}-\mathrm{Ni2}$ \\
\hline $3.0670(8)$ & $3.3216(9)$ & & & $3.064(1)$ & $3.410(2)$ \\
\hline $\mathrm{Ni5}-\mathrm{Ni} 7$ & $\mathrm{Ni5}-\mathrm{Ni3}$ & & & $\mathrm{Ni02-Ni1}$ & $\mathrm{Ni2}-\mathrm{Ni1}$ \\
\hline $3.0943(9)$ & $3.2437(9)$ & & & $3.174(1)$ & $3.323(1)$ \\
\hline \multirow{8}{*}{$\begin{array}{l}\mathrm{Ni5}-\mathrm{Ni8} \\
3.0490(9)\end{array}$} & $\mathrm{Ni5}-\mathrm{Ni} 4$ & & & & \\
\hline & $3.2274(8)$ & & & & \\
\hline & $\mathrm{Ni6}-\mathrm{Ni7}$ & & & & \\
\hline & $3.3481(9)$ & & & & \\
\hline & Ni7-Ni8 & & & & \\
\hline & $3.3049(9)$ & & & & \\
\hline & Ni6-Ni8 & & & & \\
\hline & $3.3618(8)$ & & & & \\
\hline Mean & Mean & & & Mean & Mean \\
\hline
\end{tabular}

Table 1. Comparison between $\mathrm{Ni} \cdots \mathrm{Ni}$ separations $(\AA)$ in clusters 3 and $4 \cdot 2 \mathrm{CH}_{2} \mathrm{Cl}_{2}$. 


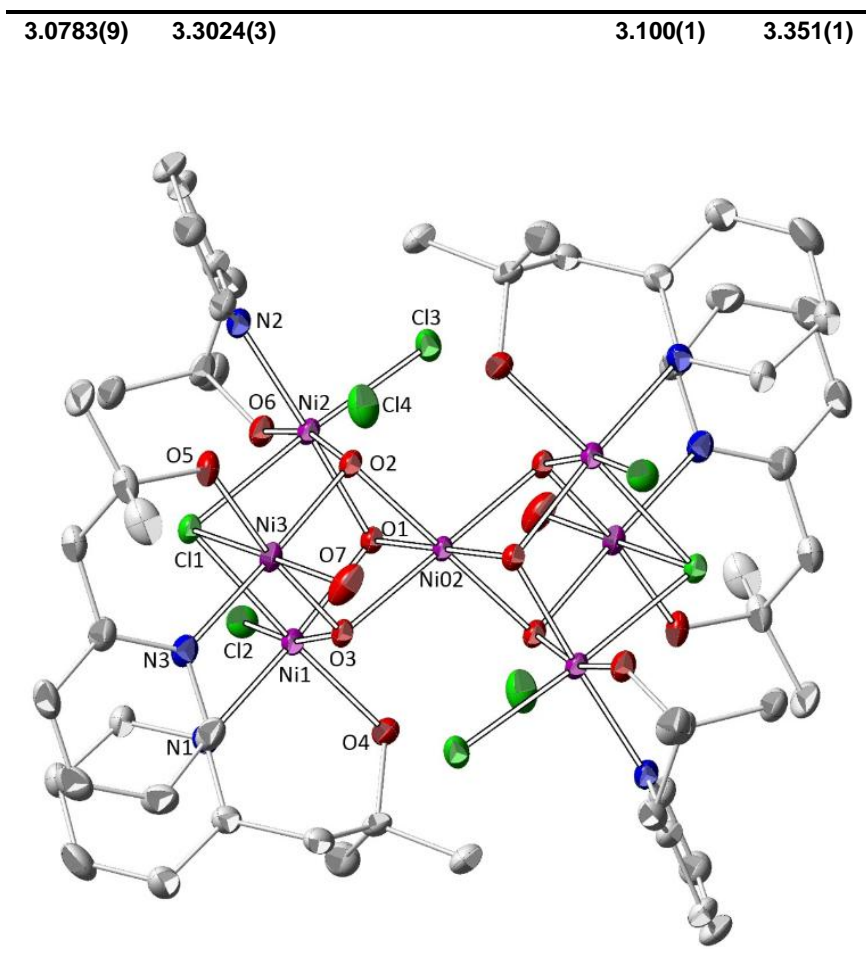

Figure 4. Diagram of the solid state structure of $\mathbf{4}$ in $\mathbf{4} \cdot 2 \mathrm{CH}_{2} \mathrm{Cl}_{2}$. Hydrogen atoms are omitted for clarity. Thermal ellipsoids are at $30 \%$ probability. Selected bond distances $(\AA)$ : Ni1-O1 2.026(3), Ni1-O3 2.039(4), Ni1-N1 2.074(4), Ni1-O4 2.093(4), Ni1-Cl2 2.414(2), Ni1-Cl1 2.588(2), Ni02-O1 2.064(4), Ni02-O2 2.068(3), Ni02-O3 2.080(3), Ni2-O1 2.030(4), Ni2-O5 2.071(4), Ni2-N2 2.073(5), Ni2-O2 2.075(4), Ni2-Cl3 2.430(2), Ni2-Cl1 2.499(2), Ni3-O3 1.996(4), Ni3-O6 2.078(4), Ni3-O2 2.089(4), Ni3-N3 2.094(4), Ni3-O7 2.106(4), Ni3-Cl1 2.457(2). For selected bond angles, see Table S1 in ESI.

In the centrosymmetric heptanuclear structure of $\mathbf{4}$, each $\mathrm{Ni}(\mathrm{II})$ metal centre is hexacoordinated and in a slightly distorted octahedral coordination environment. This complex forms a dicubane-type structure, two cubanes sharing a common vertex occupied by a Ni centre (NiO2) which is coordinated to 6 capping $\mathrm{OH}$ ligands. Within each subunit, three nickel centres (Ni1, Ni2 and $\mathrm{Ni3}$ ) are chelated by $\mathrm{HL}$ through the $\mathrm{O}$ and $\mathrm{N}$ donors and coordinated to two capping $\mathrm{OH}$ groups and one capping $\mathrm{Cl}$. For two of them (Ni2 and $\mathrm{Ni3}$ ), the coordination sphere of the nickel centre is completed by a terminal chloride and by a molecule of water for one of them (Ni3). Two external chlorides achieve the electroneutrality of the complex. In the crystal structure of $\mathbf{4}$, two molecules of dichloromethane are present. The nearest nickel centre to another molecule is Ni1, at 9.649(3) $\AA$ from Ni3. The formation of $\mathbf{4}$ is probably due to the presence of adventitious moisture in the Schlenk tube, and its synthesis could not be systematically reproduced. As expected, the longest $\mathrm{Ni} \cdots \mathrm{Ni}$ separations correspond to those bridged by two chlorides, while the shortest are those featuring $\mathrm{OH}$ bridges. The presence of both $\mathrm{Cl}$ and $\mathrm{OH}$ bridges results in intermediate values for the $\mathrm{Ni} \cdots \mathrm{Ni}$ separations.

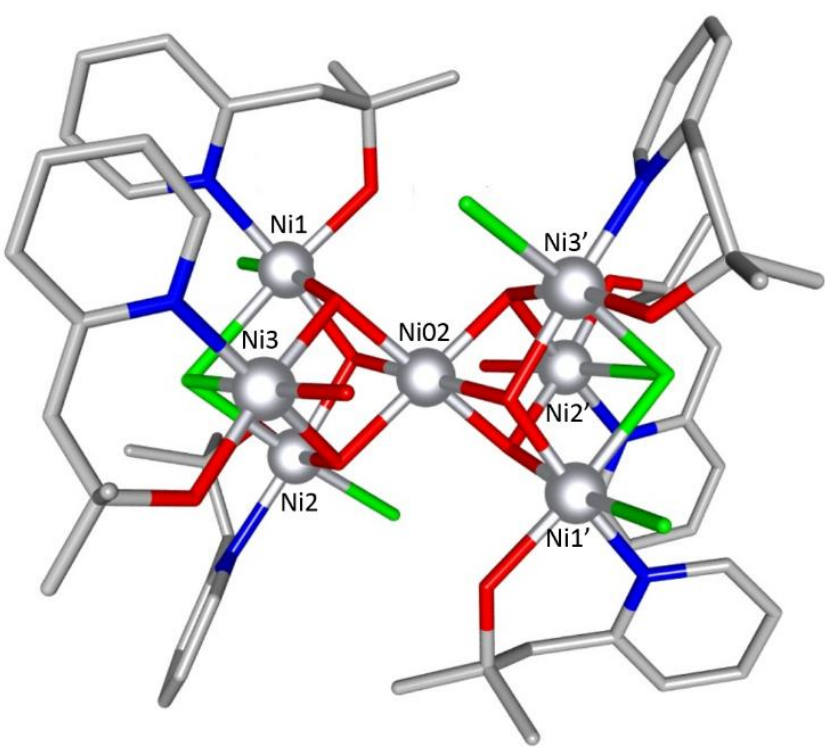

Figure 5. Simplified diagram of the solid state structure of 4 in $4 \cdot 2 \mathrm{CH}_{2} \mathrm{Cl}_{2}$.

Static Magnetic Properties

Variable-temperature dc magnetic susceptibility $\left(\chi_{\mathrm{M}}\right)$ data were measured on microcrystalline powders of complexes $\mathbf{3}$ and $\mathbf{4}$ between 2 and $290 \mathrm{~K}$ in a $10 \mathrm{kOe}$ magnetic field (Figure 6). Both complexes show Curie-Weiss behaviour, above $20 \mathrm{~K}$ for complex 4 (see Figure S1 in ESI), above $100 \mathrm{~K}$ for complex 3 (see Figure $\mathrm{S} 2$ in $\mathrm{ESI})$. We find resulting Curie constants of $11.38(2) \mathrm{cm}^{3} \cdot \mathrm{K} \cdot \mathrm{mol}^{-1}$ and $8.90(4) \mathrm{cm}^{3} \cdot \mathrm{K} \cdot \mathrm{mol}^{-1}$, respectively. This is in good agreement with 8 and 7 uncorrelated $\mathrm{Ni}$ (II) cations, with average Landé factors $g$ of 2.38 and 2.25 , respectively, as expected for $d^{8} \mathrm{Ni}(\mathrm{II})$ ions with a ${ }^{3} \mathrm{~A}_{2}$ ground state because of spin-orbit coupling. The Weiss temperatures of +13.1 (1) $\mathrm{K}$ and $+6.8(1) \mathrm{K}$ show the likely occurrence of ferromagnetic interactions. Accordingly, upon cooling, the value of $\chi_{M} T$ continuously increases and reaches a maximum of $31.1 \mathrm{~cm}^{3} \cdot \mathrm{K} \cdot \mathrm{mol}^{-1}$ at $3.0 \mathrm{~K}$ and $14.9 \mathrm{~cm}^{3} \cdot \mathrm{K} \cdot \mathrm{mol}^{-1}$ at $3.5 \mathrm{~K}$, respectively. For complex 3 , the former value supports either a $S=7$ ground state with a $g=2.11$ value $\left(31.2 \mathrm{~cm}^{3} \cdot \mathrm{K} \cdot \mathrm{mol}^{-1}\right)$, or even a $S=8$ ground state with significant anisotropy. For complex 4, the value of $14.9 \mathrm{~cm}^{3} \cdot \mathrm{K} \cdot \mathrm{mol}^{-1}$ is compatible with the spin-only value expected for a $S=5$ ground state with a $g=2.0$ value $\left(15.0 \mathrm{~cm}^{3} \cdot \mathrm{K} \cdot \mathrm{mol}^{-1}\right)$. For complex $4, \chi_{\mathrm{M}} \mathrm{T}$ decreases slightly at lower temperatures to reach $13.4 \mathrm{~cm}^{3} \cdot \mathrm{K} \cdot \mathrm{mol}^{-1}$ at $1.8 \mathrm{~K}$, showing that there are either intra- or intermolecular antiferromagnetic interactions and/or single-ion/cluster magnetic anisotropy. For both complexes an unambiguous determination of the ground state $S$ value proved to be quite difficult, as was recently observed in a similar $\mathrm{Ni}_{7}$ cluster, ${ }^{[7 \mathrm{~b}]}$ and contrary to what we observed for complex $2 .^{[5]}$

Starting with the more symmetrical complex 4 , the magnetic topology is nevertheless not so trivial, mixing $\mathrm{NiO}_{6}$, $\mathrm{NiO}_{4} \mathrm{NCl}$, cis- and trans- $\mathrm{NiO}_{3} \mathrm{NCl}_{2}$ chromophores, with magnetic interactions mediated through $\mu_{3}-\mathrm{OH}$ and $\mu_{3}-\mathrm{Cl}$ bridges. For $\mu_{3}^{-}$ 
$\mathrm{OH}$ bridges, magneto-structural correlations are known with ferromagnetic (antiferromagnetic) interactions for $\mathrm{Ni}-\mathrm{O}-\mathrm{Ni}$ angles close to $90^{\circ}$ (above about $\left.100^{\circ}\right),{ }^{[8]}$ which is evidenced by an abundant literature on oxygen-bridged polynuclear nickel complexes. ${ }^{[9]}$ For $\mu_{3}-\mathrm{Cl}$ bridges data are much more scarce and not very conclusive. ${ }^{[\mathrm{bb}, 10]}$ Indeed, even for simpler $\mathrm{Ni}_{2}\left(\mu_{2}-\mathrm{Cl}\right)_{2}$ moieties, no clear magneto-structural correlations could be extracted, though magnetic interactions are usually small $\left(\ll<10 \mathrm{~cm}^{-1}\right)$, in agreement with long $\mathrm{Ni}-\mathrm{Ni}$ distances. ${ }^{[11]}$ The crystal packing of compound $4 \cdot 2 \mathrm{CH}_{2} \mathrm{Cl}_{2}$ shows that the complexes are isolated, with no significant intermolecular contacts and the shortest distances to neighbouring molecules are above $1 \mathrm{~nm}$.

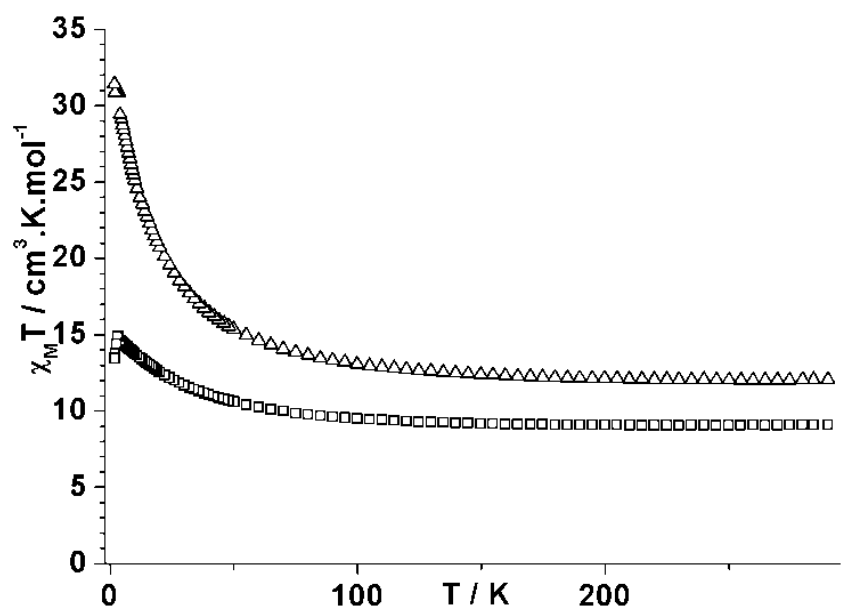

Figure 6. Plot of the magnetic susceptibility product with temperature vs. T for complex $\mathbf{3}$ (triangles) and $\mathbf{4}$ (squares).

In the light of these considerations, we can expect (see Table 1 and Table $\mathrm{S} 1$ in $\mathrm{ESI}$ ) ferromagnetic interactions between $\mathrm{NiO2}$ and $\mathrm{Ni} 1-\mathrm{Ni} 3$, and, neglecting the chlorine-mediated interactions, antiferromagnetic interactions between external $\mathrm{Ni}$ (II) cations. We simplified the spin topology considering two equilateral $\mathrm{N} 1$ $\mathrm{Ni2}-\mathrm{Ni3}$ triangles equivalent through the inversion centre with isotropic spins, with the following spin Hamiltonian

$$
\widehat{H}_{S}=-2 J \sum_{i \neq j \in[1,3]} \widehat{S_{l}} \widehat{S}_{J}-2 J \sum_{i \neq j \in[4,6]} \widehat{S}_{l} \widehat{S}_{J}-2 J^{\prime} \widehat{S_{02}} \sum_{S=1}^{6} \widehat{S}_{l}
$$

where $\widehat{S_{l}}=1$ to 6 and $\widehat{S_{T}}$ is are spin operators corresponding to the 6 peripheral $\mathrm{Ni}(\mathrm{II})$ ions and the total spin, respectively. Following the Kambe approach, ${ }^{[12]}$ we derived an analytical solution $^{[13]}$ in the form of a polynomial expression of variables $x=e^{-J^{\prime} / k T}, y=e^{-J / k T}$ (see Figure S3 in ESI). Fitting the $\chi_{\mathrm{M} T}$ experimental values showed the $J, J$ ' (and $g$ ) values to be heavily correlated, with very close ground states with $S=1$, favoured by antiferromagnetic interactions between external $\mathrm{Ni}(\mathrm{II})$, and $S=7$, favoured by ferromagnetic interactions between the apical $\mathrm{NiO2}$ and external $\mathrm{Ni}(\mathrm{II})$ cations. We checked the obtained values with softwares that directly diagonalizes the temperature- and field-dependent Hamiltonian. ${ }^{[14]}$, which showed that there is likely close competition between antagonist interactions in compound 4, this without taking into account anisotropic effects which are usually found in $\mathrm{Ni}(\mathrm{II})$ complexes. The best fitting set of values yields ferromagnetic interactions between external $\mathrm{Ni}(\mathrm{II})$ cations, and a very weak antiferromagnetic interaction between apical $\mathrm{Ni02}$ and external $\mathrm{Ni}$ (II) cations $\left(J=+2.8(1) \mathrm{cm}^{-1}, \quad J^{\prime}=-0.016(1) \mathrm{cm}^{-1}\right.$, and $g=2.233(7)$, see Figure S3 in ESI), in apparent contradiction with conclusions drawn from magnetostructural correlations on $\mathrm{Ni}-\mathrm{O}-\mathrm{Ni}$ angles. This model supports thus a $S=5$ ground state for the complex, in agreement with isothermal magnetization curves (see Figure S4 in ESI), the small antiferromagnetic interactions with the central $\mathrm{Ni}(\mathrm{II})$ inducing low-lying excited states of higher multiplicity. The combination of those low-lying excited states with magnetic anisotropy induces a dependence of the maximum value observed for the $\chi_{M} T$ product on the magnetic field applied for the measurement, making the estimation of the ground spin state more difficult. The small magnitude of the ferromagnetic coupling constant obtained between peripheral ions is striking when considering the higher value obtained in complex $2\left(\mathrm{~J}=11.5 \mathrm{~cm}^{-1}\right),{ }^{[5]}$ in which the $\mathrm{Ni}-\mathrm{Cl}$ $\mathrm{Ni}$ angles are similar (on average $85.5^{\circ}$ vs. $83.6^{\circ}$ for complex 4 ), but the $\mathrm{Ni}-\mathrm{Ni}$ distances are much longer (on average 3.5783(3) $\AA$ vs. 3.351(1) $\AA$ for complex 4). The intermediate Ni$\mathrm{Ni}$ distance in 4 supports competition between reinforced chlorine-mediated ferromagnetic interactions and weakened hydroxo-mediated antiferromagnetic interactions, resulting in an overall weak ferromagnetic interaction. Simultaneous simulations of susceptibility and isothermal magnetization curves proved to be inconclusive, certainly due to the smallness of magnetic interactions combined with the presence of magnetic anisotropy.

For complex 3, almost all $\mathrm{Ni}(\mathrm{II})$ coordination spheres differ: $\mathrm{NiO}_{5} \mathrm{Cl}$ (Ni5), cis- and trans- $\mathrm{NiO}_{3} \mathrm{NCl}_{2}$ (Ni6-Ni8), cis- $\mathrm{NiO}_{2} \mathrm{Cl}_{3}$ (Ni2), cis- $\mathrm{NiO}_{2} \mathrm{Cl}_{4}$ (Ni3-Ni4) and trans- $\mathrm{NiO}_{2} \mathrm{~N}_{2} \mathrm{Cl}_{2}$ (Ni1), with no less than 7 different magnetic interactions mediated through $\mu_{3}-$ $\mathrm{OH}, \mu_{3}-\mathrm{Cl}$ and $\mu_{2}-\mathrm{Cl}$ bridges, the latter corresponding to the longest $\mathrm{Ni}-\mathrm{Ni}$ distances (see Table 1). No convenient symmetry allowed us to try for complex 3 with its $3^{8}=6561$ microstates the modelling we used for complex 4. Again molecules of $\mathbf{3}$ are isolated from each other by the organic ligands, and the crystal packing reveals no strong or outstanding intermolecular contacts, the shortest distances are all above $0.9 \mathrm{~nm}$. The $S=7$ or $S=8$ ground state evidenced by the $\chi_{M} T$ product maximum at low temperatures is surprising given the numerous $\mathrm{Ni}-\mathrm{O}-\mathrm{Ni}$ angles close to or above $100^{\circ}$ (see Table S1 in ESI), which would rather be associated with antiferromagnetic interactions. Clearly and similarly to what was evidenced for complex 4, the increase in $\mathrm{Ni}-\mathrm{Ni}$ distances caused by the chlorine bridges weakens significantly the antiferromagnetic interactions mediated by the hydroxo bridges.

The reduced isothermal magnetization curves show a less pronounced nesting behaviour than for compound 4 (see Figure $\mathrm{S} 5$ in ESI). The measurement at $1.8 \mathrm{~K}$ reaches a value of $18.3 \mu_{\mathrm{B}}$ without saturating, a value that precludes the $S=7$ ground state, and rather supports a $S=8$ ground state that is reached only at the lowest temperatures. Indeed, simulations 
with the simple spin Hamiltonian $\widehat{H}=D \hat{S}_{z}^{2}+g \mu_{B} H \hat{S}$ show a definite change in behaviour below $5 \mathrm{~K}$, where magnetizations at 3 and $1.8 \mathrm{~K}$ are fairly well reproduced for a $S=8$ ground state with $g=2.3$ and $D=-0.25 \mathrm{~cm}^{-1}$, while for the data at $5 \mathrm{~K}$, the simulated curve lies clearly above the experimental one. Disagreements may be due to an expected anisotropy in $g$, and the possible occurrence of a rhombic component of Zero-Field Splitting, which are impossible to unambiguously determine on a measurement performed on powder. Moreover, as seen above, this $S=8$ ground state is clearly not well isolated from lower spin excited states. This was confirmed by High-Field EPR measurements which did not show features attributable to such a $S=8$ spin system down to $5 \mathrm{~K}$. Usually this technique allows a precise determination of Zero-Field Splitting parameters, ${ }^{[16]}$ as performed previously with a related $\mathrm{Ni}_{7}$ cluster. ${ }^{[7 \mathrm{~b}]}$ The few features seen are rather in agreement with contributions from either isolated ions or the coupling of only a few spins within the molecule in the temperature range of the EPR measurements (5 to $30 \mathrm{~K})$.

\section{Dynamic Magnetic Properties.}

$\mathrm{Ni}$ (II) shows consistently high magnetic anisotropy, as demonstrated by previous examples of $\mathrm{Ni}$-based Single Molecule Magnets, as was evidenced previously for complex $2{ }^{[5]}$ and more specifically a $\mathrm{Ni}_{7}$ cluster that shares some common features with compound $4:^{[7 b]}$ centrosymmetry at the apical $\mathrm{Ni}$, low-lying excited states as demonstrated by High Field EPR spectroscopy. Since centrosymmetry at the apical $\mathrm{Ni}(\mathrm{II})$ insures that the single-ion magnetic anisotropy contributions of the external cations are mathematically cancelled, leaving only the apical $\mathrm{Ni}$ (II) contribution to the overall cluster magnetic anisotropy, it is not surprising that this $\mathrm{Ni}_{7}$ cluster showed magnetic hysteresis, proving thus Single-Molecule Magnet behaviour. ${ }^{[7 \mathrm{~b}]}$ Consequently, we checked whether some slow relaxation of the magnetization could be detected in the out-ofphase magnetic susceptibility $\chi$ " for both complexes. At $1.5 \mathrm{~K}$, from 0.5 to $70 \mathrm{kHz}$, the ac magnetic susceptibility of compound 4 shows no significant deviation from zero of its dispersion component $\chi$ " (see Figure S6 in the ESI). The $\chi^{\prime} \mathrm{T}$ product (see Figure $\mathrm{S} 7 \mathrm{in} \mathrm{ESI}$ ) is stable at $1.5 \mathrm{~K}$ at the $15.0 \mathrm{~cm}^{3} \cdot \mathrm{K} \cdot \mathrm{mol}^{-1}$ value observed previously in the dc measurement (see Figure 6), supporting thus the $S=5$ ground state, and that the decrease observed previously for the $\chi_{M}{ }^{\top}$ product below $3.5 \mathrm{~K}$ is due to anisotropy effects. Applying a small dc magnetic field shifts energy levels and by lifting energy degeneracy suppresses quantum tunneling of the magnetization between $\pm \mathrm{M}_{\mathrm{S}}$ states,${ }^{[15]}$ allowing thus to observe slow relaxation if present. The same ac measurement performed under 500 Oe shows a definite increase of $\chi$ " above $30 \mathrm{kHz}$ below $2 \mathrm{~K}$ up to some $10 \%$ of $\chi$ " (see Figure S8 in ESI). Though maxima were not observed to evidence whether this behaviour is frequency-dependent or not, this result suggests that some slow relaxation behaviour may be present at lower temperatures.

For complex 3, the ac susceptibility measurement $(0.5-70 \mathrm{kHz}$, $1.5-3.9 \mathrm{~K}$, see Figure 7) shows the occurrence of a signal in dispersion below $3.3 \mathrm{~K}$, with frequency-dependent maxima. The $\chi$ 'T product plateau at $32 \mathrm{~cm}^{3} \cdot \mathrm{K} \cdot \mathrm{mol}^{-1}$ above $3.3 \mathrm{~K}$ (see Figure
S9 in ESI) is in good agreement with the dc measurement. The $\chi$ " maxima values are about $25 \%$ of the in-phase $\chi$, resulting in flattened Argand plots (see Figure S10 in ESI). Nevertheless, these Argand plots could be satisfactorily fitted below $3 \mathrm{~K}$ with an extended Debye model considering a distribution of relaxation times, ${ }^{[17]}$ with $\alpha$, being the width of the temperaturedependent $\tau$ distribution, going from 0.2 at $3 \mathrm{~K}$ to 0.5 at $1.5 \mathrm{~K}$ (see equations and results in Figure $\mathrm{S} 10$ in ESI). The good agreement found with this extended Debye model supports a single relaxation mode, with distributed characteristic times, rather than the superposition of different modes. Compound 3 behaves thus as a Single-Molecule Magnet (SMM), for which the relaxation time should follow the relation:

$$
\tau(T)=\tau_{0} e^{\frac{\Delta}{k T}}=\tau_{0} e^{\frac{|D| S^{2}}{k T}}
$$

in which $D<0$ is the cluster uniaxial zero-field splitting parameter and $S$ the total spin.
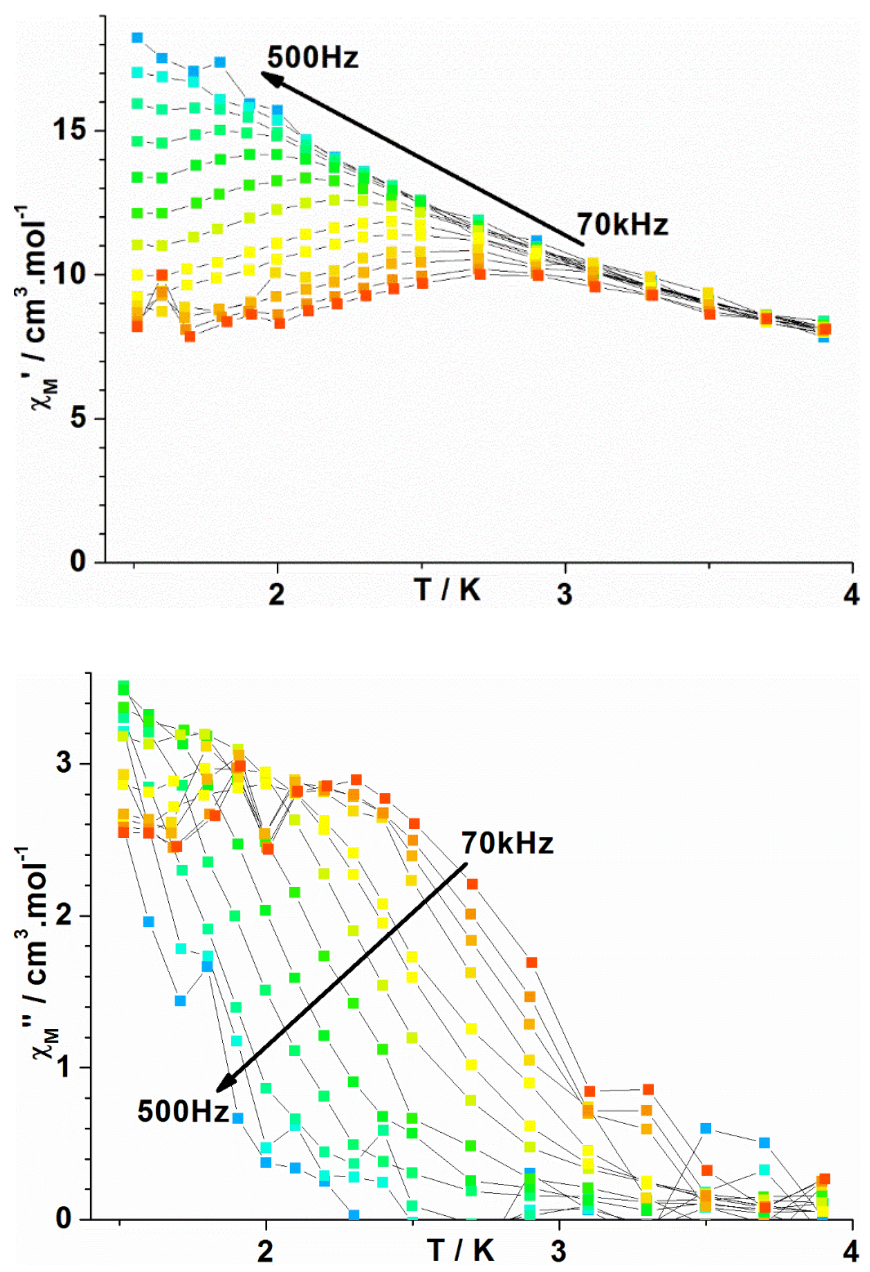

Figure 7. Temperature and frequency dependence of in-phase ( $\chi^{\prime}$, top) and out-of-phase ( $\chi$ ", bottom) components of the ac susceptibility of compound 3 . Black lines are guides to the eye. 
The Arrhenius plot of $\ln \tau(T)$ vs. 1/T shows the expected linear dependence (Figure 8), with $\tau_{0}=8.3(27) \times 10^{-9} \mathrm{~s}^{-1}$ and $\Delta=9.4(5) \mathrm{cm}^{-1}$. The $\tau_{0}$ value is in line with those usually observed for SMMs $\left(10^{-10}-10^{-8}\right)$, while the energy barrier $\Delta$ is lower than the $|D| \mathrm{S}^{2}$ value of $16 \mathrm{~cm}^{-1}$ for the supposed ground state, as is usually the case for SMMs. ${ }^{[17 b]}$ Moreover, complex 3 as we saw has a ground state that is not clearly isolated from low-lying excited states of different spin multiplicity.

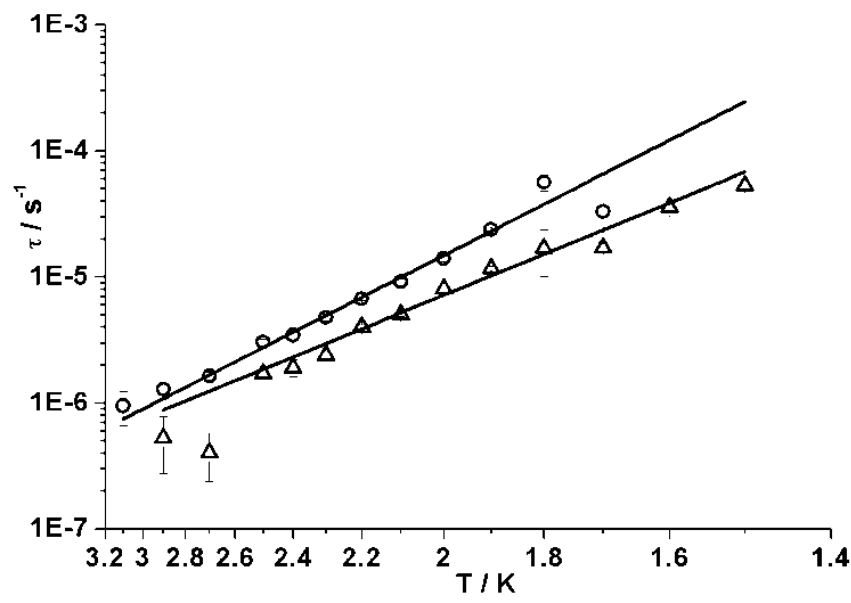

Figure 8. Arrhenius plot derived from the Debye fits of $\chi$ ' and $\chi$ " components of the ac susceptibility of compound $\mathbf{3}$, under zero Oe (triangles) and $500 \mathrm{Oe}$ (circles) magnetic fields, and corresponding linear fits.

Application of a small 500 Oe magnetic field results in a shift to higher temperature of the out-of-phase signals $\chi$ " (see Figures $\mathrm{S} 11$ and $\mathrm{S} 12$ in ESI). The Arrhenius plot (Figure 8) yields $\tau_{0}=3.3(7) \times 10^{-9} \mathrm{~s}^{-1}$ and $\Delta=11.7(3) \mathrm{cm}^{-1}$. As expected, the dc magnetic field increases the energy barrier, but also impacts $\tau_{0}$ which decreases. The value of $\alpha$ varies similarly to the zero-field situation from 0.1 at $3.5 \mathrm{~K}$ to 0.5 at $1.7 \mathrm{~K}$.

\section{Conclusions}

We described herein the synthesis of high nuclearity $\mathrm{Ni}(\mathrm{II})$ complexes bearing pyridine alcohol ligands. Depending on the physical properties of the $\mathrm{NaOH}$ used with the original intention to deprotonate the ligand, different products were obtained. Indeed, as previously described, the reaction of the pseudocubane $\left[\mathrm{Ni}\left(\mu_{3}-\mathrm{Cl}\right)(\mathrm{Cl})(\mathrm{HL})\right]_{4}(\mathbf{1})$ with highly dispersed $\mathrm{NaOH}$ led to the formation of $\left[\mathrm{Ni}\left(\mu_{3}-\mathrm{OH}\right)(\mathrm{Cl})(\mathrm{HL})\right]_{4}(2)$, whereas the use of $\mathrm{NaOH}$ pellets afforded $\left[\mathrm{Ni}_{8}\left(\mu_{3}-\mathrm{Cl}_{3}\left(\mu_{3}-\mathrm{OH}\right)_{5}(\mu-\mathrm{Cl})_{2} \mathrm{Cl}_{6}(\mathrm{HL})_{7}\right]\right.$ (3). These differences were explained by the lower reactivity of the latter (less active surface). In both cases, the ligand remained protonated but the hydroxide ion acted as a nucleophile and substituted chloride ligands. Subtle changes in the properties of the reactants may thus dramatically influence the nature of the products obtained. The octanuclear complex $\mathbf{3}$ was more conveniently prepared by the condensation of the two chemically different cubanes $\mathbf{1}$ and $\mathbf{2}$. This novel synthetic approach to higher nuclearity clusters should have a promising potential. During the course of the syntheses which led to the isolation of $\mathbf{3}$, a new heptanuclear complex, $\left[\mathrm{Ni}_{7}\left(\mu_{3}-\mathrm{Cl}\right)_{2}\left(\mu_{3^{-}}\right.\right.$ $\left.\mathrm{OH})_{6} \mathrm{Cl}_{4}\left(\mathrm{H}_{2} \mathrm{O}\right)_{2}(\mathrm{HL})_{6}\right] \mathrm{Cl}_{2}$ (4), was isolated once. The magnetic properties of $\mathbf{3}$ and $\mathbf{4}$ were investigated and highlight the unexpected ferromagnetic coupling induced by the chlorido bridges, which by lengthening the $\mathrm{Ni}-\mathrm{Ni}$ distances weaken significantly the competing antiferromagnetic interaction mediated by the capping hydroxyl ligands. Clear evidence of Single-Molecule Magnet behaviour could be found for complex $\mathbf{3}$, with field-dependent slow relaxation of the magnetization as evidenced by ac susceptometry, even though this complex shows evidence of low-lying excited spin states. Such a behaviour can only be postulated for complex 4 at lower temperatures.

\section{Experimental Section}

Ligand $\mathrm{HL}$ and complexes $\mathbf{1}$ and $\mathbf{2}$ were prepared following published procedures. ${ }^{[5,6]}$ All reactions were performed under dry Argon using standard Schlenk techniques. All solvent used were freshly distilled before use. The FTIR spectra were measured between 500 and $4000 \mathrm{~cm}^{-1}$ with a $1 \mathrm{~cm}^{-1}$ resolution on a diamond GladiATR mounted on a Shimadzu IRAffinity1 FTIR spectrometer. Unless otherwise stated, all products were commercially available and used as received. $\mathrm{NaOH}$ pellets were dried under vacuum at $100{ }^{\circ} \mathrm{C}$ during $8 \mathrm{~h}$ before use.

\section{Preparation of $\left[\mathrm{Ni}_{8}\left(\mu_{3}-\mathrm{Cl}\right)_{3}\left(\mu_{2}-\mathrm{Cl}\right)_{2}(\mathrm{Cl})_{6}\left(\mu_{3}-\mathrm{OH}\right)_{5}(\mathrm{HL})_{7}\right](3)$}

a) $\mathrm{NaOH}$ (ca. $2 \mathrm{~mm}$ spheres, $39.7 \mathrm{mg}, 0.99 \mathrm{mmol}$ ) was added to a yellow suspension of 1 (268 $\mathrm{mg}, 0.239 \mathrm{mmol})$ in dichloromethane $(15 \mathrm{~mL})$. The reaction mixture was stirred in an ultrasound bath to activate the $\mathrm{NaOH}$ pellets. The slurry was stirred for 9 days at room temperature. After 2 days the reaction mixture colour turned from yellow to green. After 9 days, most of the product was soluble in dichloromethane. A pale green precipitate was separated by filtration. The solution was layered with $\mathrm{Et}_{2} \mathrm{O}$, giving green crystals of 3 . Yield (based on nickel): $0.050 \mathrm{~g}, 17 \%$.

b) Solid 1 (200 mg, $0.18 \mathrm{mmol}$ ) was added to a solution of 2 (250 mg, $0.24 \mathrm{mmol})$ in $\mathrm{CH}_{2} \mathrm{Cl}_{2}(50 \mathrm{~mL})$. The reaction mixture was stirred for $6 \mathrm{~h}$ The solution was filtered and the filtrate was layered with $\mathrm{Et}_{2} \mathrm{O}$, which afforded green crystals of 3 . Yield (based on Ni): $164 \mathrm{mg}, 42 \%$. FTIR ( $\mathrm{v}$, $\mathrm{cm}^{-1}$, Figure S13 in ESI): 598.9, 735.4, 758.5, 791.8, 838.1, 879.1, 916.7, $1025.7,1066.6,1133.2,1160.7,1182.9,1211.3,1260.0,1318.8,1347.3$, 1373.3, 1390.7, 1426.4, 1449.0, 1486.2, 1573.4, 1609.6, 1633.2, 2817.5, 2887.5, 2979.1, 3124.7, 3213.0, 3428.5, 3300.7. Elemental analysis calcd (\%) for $\mathrm{C}_{63} \mathrm{H}_{96} \mathrm{Cl}_{11} \mathrm{~N}_{7} \mathrm{Ni}_{8} \mathrm{O}_{12}$ : C 37.78, $\mathrm{H} 4.83, \mathrm{~N} 4.90$; found: $\mathrm{C}$ $37.27, \mathrm{H} 5.14, \mathrm{~N} 4.61$.

\section{Characterization of $\left[\mathrm{Ni}_{7}\left(\mu_{3}-\mathrm{Cl}\right)_{2}\left(\mu_{3}-\mathrm{OH}\right)_{6} \mathrm{Cl}_{4}\left(\mathrm{H}_{2} \mathrm{O}\right)_{2}(\mathrm{HL})_{6}\right] \mathrm{Cl}_{2}(4)$}

Few single crystals and a microcrystalline powder of complex 4 were obtained during crystallization attempts of 3. FTIR $\left(v, \mathrm{~cm}^{-1}\right.$, Figure S14 in ESI): 608.6, 616.3, 633.6, 648.1, 736.8, 760.0, 791.8, 839.1, 879.6, $917.2,985.7,1027.1,1067.6,1099.5,1134.2,1159.3,1182.4,1212.3$, $1260.5,1318.4,1347.3,1373.4,1391.7,1426.4,1449.6,1483.3,1574.0$, 1609.7, 1632.8, 2821.0, 2882.7, 2977.3, 3112.3, 3216.4, 3299.4, 3365.9, 3437.3, 3515.4. Elemental analysis calcd (\%) for 
$\mathrm{C}_{54} \mathrm{H}_{88} \mathrm{Cl}_{6} \mathrm{~N}_{6} \mathrm{Ni}_{7} \mathrm{O}_{14} \cdot 2 \mathrm{Cl} \cdot 11 \mathrm{H}_{2} \mathrm{O}:$ C $33.47, \mathrm{H} 5.72, \mathrm{~N} 4.34$; found $\mathrm{C} 33.28$, H 5.48, N 4.30.

\section{X-ray data collection and structure refinement}

Suitable crystals for the X-ray analysis were obtained as described above. The intensity data were collected at $173(2) \mathrm{K}$ on a Kappa CCD diffractometer ${ }^{[18]}$ (graphite monochromated Mo-Ka radiation, $\lambda=0.71073 \AA$ ). Crystallographic and experimental details for the structures are summarized in Table 2. The structures were solved by direct methods (SHELXS-97) and refined by full-matrix least-squares procedures (based on $F^{2}$, SHELXL-97) ${ }^{[19]}$ with anisotropic displacement parameters for all the non-hydrogen atoms. CCDC 997512-997513 contains the supplementary crystallographic data for this paper that can be obtained free of charge from the Cambridge Crystallographic Data Center via www.ccdc.cam.ac.uk/data request/cif.

Table 2. X-ray data collection and structure refinement parameters for $\mathbf{3}$ and $4 \cdot 2 \mathrm{CH}_{2} \mathrm{Cl}_{2}$.

\begin{tabular}{lll}
\hline Compound & 3 & 4 \\
\hline Chemical formula & $\mathrm{C}_{63} \mathrm{H}_{96} \mathrm{Cl}_{11} \mathrm{~N}_{7} \mathrm{Ni}_{8} \mathrm{O}_{12}$ & $\mathrm{C}_{54} \mathrm{H}_{88} \mathrm{Cl}_{6} \mathrm{~N}_{6} \mathrm{Ni}_{7} \mathrm{O}_{14}$ \\
& & $2\left(\mathrm{CH}_{2} \mathrm{Cl}_{2}\right) \cdot 2(\mathrm{Cl})$ \\
Formula Mass & 2003.10 & 1909.73 \\
Crystal system & Orthorhombic & Monoclinic \\
$a / \AA$ & $16.143(1)$ & $14.000(4)$ \\
$b / \AA ̈$ & $27.635(2)$ & $20.342(9)$ \\
$c / \AA$ & $44.354(3)$ & $17.134(6)$ \\
$\beta /{ }^{\circ}$ & 90.00 & $118.71(2)$ \\
Unit cell volume/ $\AA^{3}$ & $19786(2)$ & $4279(3)$ \\
Temp./K & $173(2)$ & $173(2)$ \\
Space group & $P b c a$ & $P 2{ }_{1} / c$ \\
No. of formula units per unit & 8 & 2 \\
cell, $Z$ & & \\
No. of reflections measured & 52908 & 14844 \\
No. of independent reflections & 19433 & 8850 \\
$R_{\text {int }}$ & 0.0580 & 0.0421 \\
Final $R_{1}$ values $(I>2 \sigma(I))$ & 0.0520 & 0.0583 \\
Final $w R\left(F^{2}\right)$ values $(I>2 \sigma(I))$ & 0.1426 & 0.1580 \\
Final $R_{1}$ values $($ all data) & 0.0878 & 0.0982 \\
Final $w R\left(F^{2}\right)$ values $($ all data) & 0.1520 & 0.1748 \\
Goodness-of-fit on $\mathrm{F}^{2}$ & 0.976 & 1.025 \\
Largest diff. peak/hole & $-1.125 / 0.721$ e. $\AA^{-3}$ & $-0.850 / 0.826$ e. $\AA^{-3}$ \\
& & \\
\hline
\end{tabular}

\section{SQUID magnetometry and ac susceptometry}

Dc magnetic data were recorded using a MPMS-7XL Quantum Design SQUID magnetometer. Magnetic susceptibilities were measured using a RSO probe between 1.8 and $300 \mathrm{~K}$ under 1 or $10 \mathrm{kOe}$ applied field, on polycrystalline samples enclosed in heat-sealed $30 \mu \mathrm{m}$ thick polyethylene bags accurately weighed with a Mettler MX5 microbalance. Magnetizations were measured at $1.8,3,5$ and $8 \mathrm{~K}$ in the $0-70 \mathrm{kOe}$ range. Data were corrected using multipole expansion and a combination of a diamagnetic and a Curie tail for the polyethylene bag (see details in ref [20]). The diamagnetic contributions were approximated with $-1170.10^{-6} \mathrm{~cm}^{3} \cdot \mathrm{mol}^{-1}(3)$ and $-1040.10^{-6} \mathrm{~cm}^{3} \cdot \mathrm{mol}^{-1}(4)$, respectively. Temperature-independent paramagnetism, as usually found for octahedral Ni(II) $\mathrm{d}^{8}$ compounds, ${ }^{[21]}$ was corrected at $+340.10^{-6}$ (3) and $+300.10^{-6} \mathrm{~cm}^{3} \cdot \mathrm{mol}^{-1}(4)$ per nickel atom. Data for ac susceptibility were recorded on the MPMS-7XL in the lowest frequency range $(0.1-1.5 \mathrm{kHz}$, 1.8-15 K), and for higher frequency on an Oxford Instruments MAGLAB platform equipped with a homemade probe with a SRS830 Lock-in as both waveform source and detection $(0.5-90 \mathrm{kHz}, 1.5-4 \mathrm{~K})$.

\section{Acknowledgements}

We thank Dr. Vitor Rosa for experimental contributions and fruitful discussions and Mélanie Boucher for experimental assistance. We thank the CNRS, the Ministère de l'Enseignement Supérieur et de la Recherche (Paris), the Université de Strasbourg and the International Center for Frontier Research in Chemistry, Strasbourg (icFRC, www.icfrc.fr) for financial support. We thank Professors Roberta Sessoli and Andrea Caneschi in LaMM, INSTM/University of Florence, for acces to the Oxford Instruments MAGLAB platform.

Keywords: Coordination clusters $\cdot$ Cubanes $\cdot$ Molecular magnetism $\bullet$ Nickel $\bullet \underline{\mathrm{N}, \mathrm{O} \text { ligands }}$

[1] a) P. Braunstein, F. Naud, Angew. Chem. Int. Ed. 2001, 40, 680-699; b) W.-H. Zhang, S. W. Chien,T. S. A. Hor, Coord. Chem. Rev., 2011, 255, 1991-2024.

[2] a) S. Parsons,R. E. P. Winpenny, Acc. Chem. Res., 1997, 30, 89-95; b) R. E. P. Winpenny, J. Chem. Soc., Dalton Trans., 2002, 1-10; c) S. Langley, M. Helliwell, J. Raftery, E. I. Tolis, R. E. P. Winpenny, Chem. Commun., 2004, 142-143; d) S. J. Langley, M. Helliwell, R. Sessoli, P. Rosa, W. Wernsdorfer, R. E. P. Winpenny, Chem. Commun., 2005 5029-5031; e) S. Langley, M. Helliwell, R. Sessoli, S. J. Teat, R. E. P. Winpenny, Inorg. Chem., 2007, 47, 497-507; f) S. Langley, M. Helliwell, R. Sessoli, S. J. Teat, R. E. P. Winpenny, Dalton Trans., 2009, 3102$3110 ;$ g) P. L. Feng, C. C. Beedle, C. Koo, W. Wernsdorfer, M. Nakano S. Hill,D. N. Hendrickson, Inorg. Chem., 2008, 47, 3188-3204; h) J. Liu, S. Datta, E. Bolin, J. Lawrence, C. C. Beedle, E.-C. Yang, P. Goy, D. N Hendrickson, S. Hill, Polyhedron, 2009, 28, 1922-1926; i) C. C. Beedle, J. J. Henderson, P.-C. Ho, T. Sayles, M. Nakano, J. R. O'Brien, K. J. Heroux, E. del Barco, M. B. Maple, D. N. Hendrickson, Inorg. Chem. 2010, 49, 5780-5782; j) C. G. Efthymiou, A. N. Georgopoulou, C. Papatriantafyllopoulou, A. Terzis, C. P. Raptopoulou, A. Escuer, S. P. Perlepes, Dalton Trans., 2010, 39, 8603-8605; k) C. G. Efthymiou, C. Papatriantafyllopoulou, G. Aromi, S. J. Teat, G. Christou,S. P. Perlepes, Polyhedron, 2011, 30, 3022-3025; I) C. G. Efthymiou, C. P. Raptopoulou, V. Psycharis, A. J. Tasiopoulos, A. Escuer, S. P. Perlepes, C. Papatriantafyllopoulou, Polyhedron, 2013, 64, 30-37; m) L. Pham, K. A. Abboud, W. Wernsdorfer, G. Christou, Polyhedron, 2013, 66, 205-211; n) A. Ghisolfi, K. Y. Monakhov, R. Pattacini, P. Braunstein, X. López, C. de Graaf, M. Speldrich, J. van Leusen, H. Schilder, P. Kögerler, Dalton Trans., 2014, 43, 7847-7859; o) C. Lampropoulos, A E. Thuijs, K. J. Mitchell, K. A. Abboud, G. Christou, Inorg. Chem., 2014 53, 6805-6816.

[3] A. Kermagoret, P. Braunstein, Dalton Trans., 2008, 1564-1573.

[4] a) L. Kayser, R. Pattacini, G. Rogez, P. Braunstein, Chem. Commun., 2010, 46, 6461-6463; b) J. Zhang, P. Teo, R. Pattacini, A. Kermagoret R. Welter, G. Rogez, T. S. A. Hor, P. Braunstein, Angew. Chem. Int. Ed., 2010, 49, 4443-4446; c) A. Massard, G. Rogez, P. Braunstein, Dalton Trans., 2014, 43, 42-46.

[5] S. Hameury, L. Kayser, R. Pattacini, G. Rogez, W. Wernsdorfer, P Braunstein, Dalton Trans., 2013, 42, 5013-5024.

[6] F. Speiser, P. Braunstein, L. Saussine, R. Welter, Inorg. Chem., 2004, 43, 1649-1658. 
[7] a) T. D. Keene, M. B. Hursthouse, D. J. Price, New J. Chem., 2004, 28, 558-561; b) S. Petit, P. Neugebauer, G. Pilet, G. Chastanet, A.-L. Barra A. B. Antunes, W. Wernsdorfer, D. Luneau, Inorg. Chem., 2012, 51 6645-6654.

[8] a) M. S. El Fallah, E. Rentschler, A. Caneschi, R. Sessoli, D. Gatteschi, Inorg. Chem., 1996, 35, 3723-3724; b) R. Vaidhyanathan, C. A. Bridges, D. Bradshaw, M. J. Rosseinsky, Cryst. Growth Des., 2010, 10, 43484356.

[9] a) M. A. Halcrow, J.-S. Sun, J. C. Huffman, G. Christou, Inorg. Chem., 1995, 34, 4167-4177; b) J. M. Clemente-Juan, B. Chansou, B. Donnadieu, J.-P. Tuchagues, Inorg. Chem., 2000, 39, 5515-5519; c) A Das, F. J. Klinke, S. Demeshko, S. Meyer, S. Dechert, F. Meyer, Inorg. Chem., 2012, 51, 8141-8149.

[10] J.-C. Jiang, Z.-L. Chu, W. Huang, G. Wang, X.-Z. You, Inorg. Chem., 2010, 49, 5897-5911.

[11] a) E. J. Laskowski, T. R. Felthouse, D. N. Hendrickson, G. J. Long, Inorg. Chem., 1976, 15, 2908-2911; b) C. P. Landee, R. D. Willett, Inorg. Chem., 1981, 20, 2521-2525; c) G. A. van Albada, J. J. A Kolnaar, W. J. J. Smeets, A. L. Spek, J. Reedijk, Eur. J. Inorg. Chem., 1998, 1337-1341; d) O. F. Ikotun, W. Ouellette, F. Lloret, M. Julve, R. P. Doyle, Eur. J. Inorg. Chem., 2007, 2083-2088.

[12] K. Kambe, J. Phys. Soc. Jpn., 1950, 5, 48-51.
[13] E. Belorizky, J. Phys. I France, 1993, 3, 423-445.

[14] Magpack software, see a) J. J. Borrás-Almenar, J. M. Clemente-Juan E. Coronado, B. S. Tsukerblat, Inorg. Chem., 1999, 38, 6081-6088; b) J. J. Borrás-Almenar, J. M. Clemente-Juan, E. Coronado, B. S. Tsukerblat, J. Comput. Chem., 2001, 22, 985-991; PHI software, see c) N. F. Chilton, R. P. Anderson, L. D. Turner, A. Soncini, K. S. Murray, J. Comput. Chem., 2013, 34, 1164-1175.

[15] D. Gatteschi, R. Sessoli, Angew. Chem. Int. Ed., 2003, 42, 268-297.

[16] D. Gatteschi, A. L. Barra, A. Caneschi, A. Cornia, R. Sessoli, L. Sorace, Coord. Chem. Rev., 2006, 250, 1514-1529.

[17] a) K. S. Cole, R. H. Cole, J. Chem. Phys., 1941, 9, 341-351; b) D. Gatteschi, R. Sessoli, J. Villain Molecular Nanomagnets; Oxford University Press, Oxford, U.K., 2006.

[18] Bruker-Nonius Kappa CCD Reference Manual; Nonius BV, The Netherlands, 1998

[19] M. Sheldrick Acta Cryst., 2008, A64, 112-122.

[20] T. Palamarciuc, J. C. Oberg, F. El Hallak, C. F. Hirjibehedin, M. Serri, S. Heutz, J.-F. Létard, P. Rosa, J. Mater. Chem., 2012, 22, 9690-9695.

[21] R. Bóča Theoretical foundations of molecular magnetism; Elsevier, 1999 


\section{Entry for the Table of Contents}

\section{FULL PAPER}

The condensation between two chemically different tetranuclear cubane-like clusters $\quad\left[\mathrm{Ni}\left(\mu_{3}-\right.\right.$ $\mathrm{Cl})(\mathrm{Cl})(\mathrm{HL})]_{4} \quad(1) \quad(\mathrm{HL}=2$-methyl-1(pyridin-2-yl)propan-2-ol) and $\left[\mathrm{Ni}\left(\mu_{3}-\right.\right.$ $\mathrm{OH})(\mathrm{Cl})(\mathrm{HL})]_{4}(2)$ offers a new access to higher nuclearity complexes, such as $\left[\mathrm{Ni}_{8}\left(\mu_{3}-\mathrm{Cl}\right)_{3}\left(\mu_{3}-\mathrm{OH}\right)_{5}(\mu-\mathrm{Cl})_{2} \mathrm{Cl}_{6}(\mathrm{HL})_{7}\right]$ (3), which displays Single-Molecule Magnet behaviour.

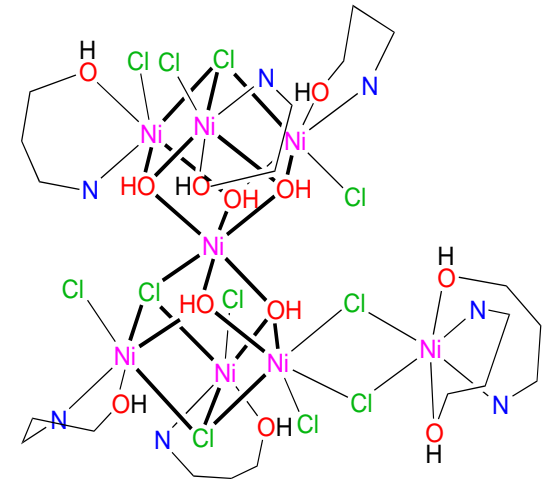

Sophie Hameury, Laure Kayser, Roberto Pattacini, Patrick Rosa, ${ }^{*}$ AnneLaure Barra and Pierre Braunstein*

Page No. - Page No.

Synthesis, Structures and Single Molecule Magnet Behaviour of High Nuclearity Ni(II) Dicubane-type Complexes with Pyridyl-Alcohol Ligands 